\title{
Projeto filosofia na Escola:
}

\section{A posição do professor, um começo de conversa.}

\author{
Gabriela Freitas de Almeida (1)
}

Resumo: A relação entre filosofia e educação torna-se confusa se nos apoiarmos na idéia de que são opostas e, muitas vezes, incompatíveis, já que a educação pode ser vista, entre outros, como transmissão, e a filosofia nos força ao questionamento. O professor, não unicamente o de filosofia, se encontra nesse fogo cruzado, carregando consigo necessidades, dúvidas e medos, que são esboçados aqui, como um começo de conversa.

Em 1997, na Universidade de Brasília, surge o projeto Filosofia na Escola como uma alternativa ao "Filosofia para Crianças", de Lipman. Suas principais críticas às novelas filosóficas de Lipman são a obrigatoriedade da utilização de livros didáticos, que possibilita que o "Filosofia para Crianças" se torne uma mercadoria para comércio, e a posição secundária do professor facilitador, que fica dependente das novelas filosóficas.

Portanto, o projeto Filosofia na Escola nasce da crítica, de um repensar o que já parecia tão certo. Nasce do olhar sob outro ponto de vista o mesmo objeto: uma sala de aula onde se faz filosofia.

Repito: "uma sala de aula onde se FAZ filosofia", pois o modo de trabalho que procuramos desenvolver no Filosofia na Escola não se refere apenas a aprender filosofia, ou entender a filosofia, mas, principalmente, fazer filosofia, esta vista como investigação e experiência do pensar.

Assim como o Filosofia na Escola é capaz de criticar outros modos de empregar a filosofia na sala de aula, também é necessário que o projeto, ou nós, que participamos dele e o fazemos acontecer, nos autocritiquemos. O repensar a si mesmo e as relações com as crianças de professores e mediadores, isto é, graduandos que atuam com os professores e crianças nas salas de aula, se faz indispensável para que não se cristalizem suas formas de atuação e seus pressupostos, para que nenhum modelo seja visto como a única forma de se fazer filosofia dentro do Filosofia na Escola, mas que cada um seja uma possibilidade.

É em nome dessa autocrítica que busco repensar as relações entre crianças e professores/mediadores numa oficina de filosofia e destes com a sua prática. Para isso, tenho como ponto de partida alguns fatos ocorridos numa escola onde essas oficinas ocorrem semanalmente. 
Porém, antes do relato desses fatos do projeto, faço uma confissão: acredito que nossos atos devam ser baseados em nossas crenças, sejam elas provindas da religião, da razão ou do que quer que seja.

O fato que mencionei anteriormente, ocorrido numa escola participante do Filosofia na Escola, e que pode nos ajudar a pensar sobre uma possível "deformação" do indivíduo pela educação, no sentido que lhe empresta Sílvio Gallo (2004), ou seja, algo a que se precisa submeter para poder ter uma saída, diz respeito a quando, após pouco mais de um semestre realizando oficinas de filosofia (que na maioria das vezes consistiam em um "pretexto" que iniciaria uma discussão, mediada pelo professor/mediador, sobre um tema qualquer) com crianças da 4 a série, utilizou-se um "pretexto" incomum quando se decidiu tratar com as crianças o papel do professor e dos estudantes numa sala de aula: após um silêncio dos professores, inesperado por parte das crianças, elas perguntam quando começaria a "aula". A resposta foi que a "aula" já havia começado, já que elas já conversavam, seguida da pergunta: Por que os professores que sempre têm que "começar a aula"?

Não foi possível conversar com grandes interessados no assunto sobre o porquê esperamos sempre que o professor norteie a discussão. Que forma de poder é essa que faz com que o professor sempre decida por todos? Como a presença dos mediadores na sala de aula só ocorre quando das oficinas de filosofia, as crianças perceberam "o que tinham que fazer" e, a seu modo, tentaram reproduzir uma das oficinas passadas, ou seja, tentavam fazer o que supunham que esperávamos delas.

Coincidentemente, fato parecido ocorreu entre adultos posteriormente. Num espaço reservado a conversas sobre assuntos referentes ao encaminhamento do projeto, antes de iniciado o tempo previsto para isso, mediadores e professores começaram a fazê-lo. Pouco depois surge a pergunta: Vamos começar a reunião? E a resposta que a segue: A reunião já começou, as duplas já estão conversando.

Analisando o primeiro fato, com as crianças, poderíamos ficar tristes por dois (ou três) motivos. Primeiro por perceber que elas já não fazem o que querem, mas sim o que nós queremos que façam. Depois por não termos discutido com elas as relações a que nos propusemos. E por último por termos nos sentido tristes por não discutirmos o que nós queríamos, por ter achado que, por não ter acontecido conforme o planejamento, o momento não foi proveitoso. Porém, percebe-se que, mesmo ainda sendo crianças, possuem e reconhecem algumas "obrigações" que têm de cumprir para o bom convívio social.

Fato parecido acontece com os adultos: existe um motivo para que fiquemos felizes por sua atitude, outro para que fiquemos tristes. Ficamos felizes porque cumpriram seu dever de bons profissionais e tristes porque, caso não seja essa a sua vontade, isso significa uma deformação do indivíduo. 
Percebemos, então, que a educação, institucionalizada ou não, torna-nos submissos, tanto adultos quanto crianças, a regras sociais que muitas vezes nos impedem de "ser nós mesmos": deformam o ser.

Como confessei anteriormente, acredito que nossos atos devam se basear em nossas crenças (ou ideologias, se preferirem). Portanto, se acreditamos que a educação, como a conhecemos, é algo ruim, que se destrua essa educação. Que a transformemos ou a destruamos ao invés de repetir seus malefícios e continuar a realizá-la como que acreditando que não o fosse. E acreditando que suas conseqüências são proveitosas, também sejamos coerentes em nossas ações e discursos. As palavras não são as únicas formas de tentar comunicar o que se pensa, a ação pode, e deve, ser uma forma de fazê-lo.

É lugar comum entre os filósofos, pedagogos e outros estudiosos atuais a afirmação de que a educação traz em si uma poderosa forma de dominação e ajustamento do indivíduo ao meio social. Nem mesmo os grandes filósofos do passado (já que, em sua maioria, só os reconhecemos como grandes filósofos depois de mortos) conseguiram em seus estudos sobre educação pensar uma forma de educação que não "deformasse" os indivíduos, que ao nos fazer seres humanos e sociais, não nos retirasse a possibilidade de não sê-lo, a liberdade de escolha, pois a educação nada mais é que uma forma de fazer do indivíduo um ser sociável que, e nesse ponto, cumpre satisfatoriamente o papel que a ela foi designado.

Que fazer, então, diante desse quase consenso que é a destruição do individual em prol do coletivo à que serve a educação? Destruir a atual educação e propor uma nova forma de educação? Propor simplesmente uma recusa à qualquer forma de educação?

A construção de uma nova educação nos levaria ao mesmo problema: à deformação do indivíduo, mudaríamos a embalagem, enfeitaríamos com pedras preciosas (como tantas vezes já o fizemos), mas o presente continuaria sendo o mesmo. Da mesma forma, formaríamos e seríamos formados. Mesmo que houvesse outras formas de agir, a base continuaria a mesma.

A recusa a qualquer forma de educação tampouco me parece viável. Esquecemonos que também somos beneficiados pela educação, uma vez que fazemos parte da sociedade e ela é ponto fundamental e primordial da vida social, já que é através dela que também a sociedade se mantém. Além disso, se considerarmos a educação como o modo como alguém se torna o que é, sendo a educação um processo constitutivo do ser humano, como afirma Pinto (1987), qualquer forma de "contra-educação" significaria a nossa não existência, ao menos como somos hoje. Não seria humano um ser que não passasse por esse processo. Mais do que perguntar sobre o que fazer para que a educação não nos deforme, torna-se necessário perguntar se realmente não queremos ou não precisamos dessa deformação.

Mas, lembrando-nos da necessidade de realizar escolhas, já que a própria negação de fazê-lo já caracteriza um caminho, como agir no mundo real em que vivemos 
sem que essa ação não signifique uma negação de um ideal de homem autônomo? Lembrando ainda de que é, no mínimo, incoerente pensar de uma forma sobre determinado assunto e agir de forma contrária, também é incoerente acreditar que a educação deforme o indivíduo (atribuindo valor negativo a essa deformação) $e$ continuar a exercê-la.

Nesse sentido, qual caminho poderia escolher um profissional da área de educação ou qualquer um que acredite nesse ideal de autonomia? Como pode um professor, acreditando que a educação realmente deforme e vendo essa deformação como algo ruim, aceitar ser autor dela? E, voltando aos professores participantes do Filosofia na Escola, como poderiam agir diante da idéia de deformação produzida pela sua ação educativa?

Uma solução seria seu afastamento da escola e da educação. Porém, atualmente, os professores não podem se dar ao luxo de escolher seu trabalho. Uma mudança de emprego exige muito mais do que vontade. Além disso, outro ponto que invalida essa solução é o próprio conceito de educação. Mesmo que afastado da instituição escolar, o professor continua educando, pois a educação não se restringe ao espaço escolar, mas acontece em todas as formas de interação social, não sendo uma escolha, já que até mesmo o silêncio e a omissão podem dizer algo e educar. A educação não depende da vontade de quem "fala", mas da interpretação de quem "ouve". É importante notar que aqui o problema da deformação deixa de se restringir ao professor passando a ser um problema de todos os que fazem parte da sociedade.

Analisando dessa forma a educação, qual seria o papel de um projeto que tenta criar espaços que possibilitem a experimentação do pensar em instituições escolares? O que estaria fazendo um projeto que objetiva a experiência do pensar num local destinado à deformação? Se filosofia e educação são antagônicas, como podem conviver em um mesmo local?

Se pensarmos no conceito dessa "deformação" como quando deixamos de ser nós mesmos devido a uma imposição do ambiente, é possível pensar também na não deformação quando as ações (ou idéias, ou conceitos, ou valores...) partissem do próprio indivíduo. Assim, não seria possível tentar não deformar outros, pois a tentativa de fazê-lo seria uma deformação, mas há a possibilidade de impedir que outros nos deformem, caso se julgue necessário, cabendo a cada pessoa lutar contra ela, ou seja, pode partir de cada um a tentativa de não se deixar deformar completamente.

Dessa forma, é possível enxergar a própria instituição educacional como um espaço, não para fabricar uma suposta autonomia, haja vista que esta é impossível, mas onde a ação do outro seja um início, um começo de conversa, não uma imposição de uma forma de ser, agir, pensar, etc, impedindo que essa deformação do educando seja a base da instituição escolar.

Portanto, mesmo dentro da escola, é possível que junto à deformação também haja o fortalecimento da capacidade do indivíduo de "autoformação". 


\section{Referências}

GALLO, Sílvio. O macaco de Kafka e os sentidos de uma educação filosófica. In. KOHAN, Walter O (org). Políticas do ensino de filosofia . Rio de Janeiro: DP\&A, 2004.

PINTO, Álvaro Vieira. Conceito de educação. In. Sete lições sobre educação de adultos. São Paulo: Cortez, 1994.

(1) Estudante do $5^{\circ}$ semestre do Curso de Pedagogia da UnB e participante do Projeto Filosofia na Escola. E-mail: gabibols@yahoo.com.br 